\title{
Adaptive phenotypic plasticity of gypsy moth digestive enzymes
}

Research Article

Marija Mrdaković ${ }^{1, *}$, Biljana Stojković ${ }^{2,3}$, Vesna Perić-Mataruga ${ }^{1}$, Larisa llijin ${ }^{1}$, Milena Vlahović ${ }^{\text {, Jelica Lazarević }}{ }^{1}$

'Department of Insect Physiology and Biochemistry, Institute for Biological Research "Siniša Stanković, University of Belgrade, 11000 Belgrade, Serbia

${ }^{2}$ Department of Evolutionary Biology,

Institute for Biological Research "Siniša Stanković",

University of Belgrade, 11000 Belgrade, Serbia

${ }^{3}$ Faculty of Biology, University of Belgrade,

11000 Belgrade, Serbia

Received 08 July 2013; Accepted 30 September 2013

\begin{abstract}
The adaptiveness of plasticity of digestive enzyme responses to allelochemical stress was tested on 32 full-sib families of gypsy moth larvae from an oak forest population (the Quercus population) and 26 families from a locust-tree forest (the Robinia population), reared either on control diet, or on tannin-supplemented diet. Using the duration of larval development as an indirectmeasure of fitness, phenotypic selection analyses revealed that lower specific activities of total proteases and trypsin, and higher specific activity of leucine aminopeptidase were adaptive for both populations in the control environment. Plasticity was only shown to be costly for total proteases and trypsin activity in Quercus larvae. In a stressful environment, the most apparent adaptive response was a significant increase in lipase activity. There was no plasticity cost for lipase activity. The two populations differed in the direction of selection acting on $\alpha$-glucosidase activity, which favoured decreased activity in Quercus larvae and increased activity in Robinia larvae in the control environment. $\alpha$-glucosidase activity in Quercus larvae is characterized by cost of homeostasis, while cost of plasticity was shown for Robinia larvae. The results obtained on the plasticity of digestive enzyme activity indicate how this generalist species copes with variation in plant allelochemicals.
\end{abstract}

Keywords: Lymantria dispar L. • Allelochemical stress • Response to selection • Cost of plasticity

(C) Versita Sp. z 0.0.

\section{Introduction}

Phenotypic plasticity, the capacity of individuals of the same genotype to express different phenotypes in different environments, is an important mechanism by which a population can respond rapidly to changing environmental conditions [1]. Adaptive plasticity can evolve toward expression of the optimal phenotype in each environment, if there is genetic variation of trait plasticity and selection on it. Evolution of adaptive plasticity may be constrained by genetic correlations across environments and by the costs of plasticity $[2,3]$. Since complex life-history traits are composed of many subordinate traits, the response to selection, which acts most strongly on those phenotypic aspects that are most strongly correlated with fitness, comprises associated changes in both mean values and plasticity of various aspects of morphology, physiology, and biochemical pathways [4-6]. Analyses of the relationships between plasticity of these numerous traits and lifehistory characteristics of organisms can improve our understanding of diverse adaptations that evolve in populations inhabiting heterogeneous environments.

Phytophagous insects express a variety of phenotypic responses to the quality of their hosts, such as changes in behavioral, morphological, and life-history traits [7-11]. Considerable plasticity of digestive enzyme activity in response to variation in the nutritive and antinutritive characteristics of host plants has also been detected in these insects [12-14]. Many plant secondary 
compounds may bind to plant protein, preventing its digestion, or reduce the activity of digestive enzymes (such as total serine proteinase, trypsin, aminopeptidase [15,16], amylase [17], and glucosidase [18]), or affect enzyme regulation [13], thus hampering food digestion. On the other hand, insects can respond to these challenges through quantitative changes, i.e. changes of the levels of enzyme activity, and/or qualitative changes, i.e. synthesis of less sensitive or insensitive enzyme forms. As serine proteases contribute to about $95 \%$ of the total digestive activity in lepidopteran larvae, their functional diversity plays a key role in the response to different plant compounds [19]. Dynamic modulation of digestive enzyme activity could be the basis of insect adaptation to various host plants [20]. The role of plasticity of enzyme activity in the evolution of specific adaptations on different hosts can best be understood by analyzing phytophagous insects which survive and feed on a large range of host plants, i.e., generalist species. Specifically, it is expected that plastic adjustments of enzyme activity are of crucial importance for coping with a variety of plant chemicals in order to maintain at least sufficiently functioning life-history strategies to survive and reproduce.

Lymantria dispar (Linnaeus) (Lepidoptera: Lymantriidae) is one of the most important insect pests in broadleaf forests of the Northern Hemisphere. It can feed on more than 500 plant species [21]. Considering the tremendous variety of host-specific chemical defenses, it can be expected that the digestive enzyme activity of the gypsy moth is exposed to a wide range of selective pressures and that the evolution of enzyme plasticity could be one of the major ways to adapt to heterogeneous host environments. The gypsy moth is considered a tannin-tolerant herbivore [22], although higher tannin levels in leaves or increased tannin concentration in an artificial diet has been shown to decrease fitness in this species [23-25]. In our previous study, we reported adverse effects of a tannin-supplemented rearing diet on some larval traits in gypsy moths originating from two populations: oak and locust-tree forests [26]. Here, we present the results of an experiment performed on the same two populations. Hydrolyzable tannins have been detected in both oak and locust-tree leaves [24,27,28], but importantly, locust-trees have higher levels of tannin [28]. As part of quantitative plant defense, these allelochemicals could be the agents of selection on gypsy moth larvae. As expected after more than 50 years of independent evolution of these two populations [29], significant between-population divergence has been revealed for various life-history, behavioral, and physiological traits [30-32]. Regarding enzyme plasticity, previously published results [33] revealed changes in total protease, $\alpha$-glucosidase, and lipase activity in response to a tannin-supplemented rearing diet. Quantitative genetic analysis has detected significant expression of genetic variation of enzyme activity and enzyme plasticity within populations, indicating that there is potential for the evolution of adaptive plastic responses to new or otherwise stressful environments [33]. Also, the specific activity of trypsin decreased, while leucine aminopeptidase activity showed a tendency to increase in response to a tannin-supplemented rearing diet. Significant variability of enzyme plasticity was demonstrated in both Quercus and Robinia populations [34]. Changes in the activity of five digestive enzymes and the duration of larval development are also given in the present study.

Our aim was to assess the adaptive significance of plasticity of the five previously listed enzymes in response to allelochemical stress imposed by increasing tannic acid in the rearing diet. Specifically, gypsy moth larvae from two populations, oak and locust-tree, were exposed to two different experimental conditions: control and stressful environment. In order to quantify the intensity of selection on the specific activities of digestive enzymes in each environment and on the plasticity of these activities, we used developmental time as an indirect measure of fitness. Our premise was that acceleration of larval development is positively correlated with higher net fitness in this species. As reviewed in Nylin and Gotthard [35], in some species and specific ecological circumstances, such as species with opportunistic lifestyles and fluctuating population dynamics, a short developmental time should be considered beneficial. However, shorter juvenile development could lead to smaller size at maturity. The theory on optimal insect size involves the trade-off between fitness advantage of large size, and disadvantage of prolonged juvenile development. Although prolonged development can be a way of increasing food consumption on a suboptimal diet [36], it can also result in longer exposure of young and more vulnerable larvae to natural enemies [37]. Young larvae have greater sensitivity to secondary plant compounds and mechanical leaf traits [38-40], and their mortality is higher [41]. Considering these facts, a shorter duration of larval stage, especially of younger larval instars, should be adaptive and contribute to fitness. In the gypsy moth, larval development time increased and pupal weight decreased in response to low protein (nitrogen) diets and higher concentrations of some plant secondary compounds [42-44]. In an experiment with natural host plants, Lazarević et al. [45] failed to detect the trade-off between the duration of larval development and pupal weight or fecundity in the gypsy moth. A significant negative correlation 
was recorded between development time and weight in gypsy moth larvae reared on a low-quality artificial diet [46]. Therefore, based on these premises and earlier studies, in our analyses of patterns of selection we considered negative correlation between enzyme and developmental time to be an indicator of positive selection on enzyme activity in specific environments and populations, whereas the cost of plasticity was indicated by the positive correlation between enzyme plasticity and developmental time.

\section{Experimental Procedures}

\subsection{Experimental design}

As described previously [26,33], the experiment was performed on larvae of the gypsy moth Lymantria dispar from two populations with different host use histories (oak and locust-tree). Thirty-two gypsy moth egg masses were collected from a mixed oak forest within the Bogovadja forest complex, referred to as the Quercus population (locality "Bogovadja", $70 \mathrm{~km}$ south-west of Belgrade). Twenty-six egg masses were collected from a locust-tree (Robinia pseudoacacia L.) forest, referred to as the Robinia population (locality "Bagremara", near Bačka Palanka, 122 km north-west of Belgrade). Egg masses were kept in the refrigerator at $4^{\circ} \mathrm{C}$ until transferring to a constant temperature of $23^{\circ} \mathrm{C}$ for hatching. Larvae were reared at $23^{\circ} \mathrm{C}$ and a photoperiod of L12:D12. Fresh food was supplied daily.

All larvae hatched from a single egg mass represented full-sibs. From both populations within each egg mass 7-9 larvae were randomly assigned to two groups: a group fed on the control diet, C (HWG diet for gypsy moth, according to O`Dell et al. [47]), and a group fed on the HWG diet containing 5\% tannic acid, T (5\% dry weight, Sigma Aldrich, lot No 32K1248). Four experimental groups were created: 1) QC, Quercus larvae fed on the control diet; 2) QT, Quercus larvae fed on the tannin-supplemented diet; 3) RC, Robinia larvae fed on the control diet; and 4) RT, Robinia larvae fed on the tannin-supplemented diet.

Duration of development (in days) from hatching until moulting into the fourth instar $\left(L_{4}\right)$, duration of fourth instar $\left(\mathrm{L}_{4}\right)$, and developmental time from hatching until moulting into the fifth instar $\left(\mathrm{LD}_{5}\right)$ were determined for each larva. Values of these traits, representing lifehistory characteristics in sequential temporal order within the larval period, were used as indirect measures of individuals' fitness. On the third day of the fifth instar, larvae were sacrificed, and their midguts were removed by dissection and homogenized individually in $0.15 \mathrm{~mol} \mathrm{~L}^{-1} \mathrm{NaCl}$ (final tissue concentration $100 \mathrm{mg} \mathrm{ml}^{-1}$ ).
After centrifugation at $10,000 \times \mathrm{g}$ for $20 \mathrm{~min}$ at $4^{\circ} \mathrm{C}$, the supernatants (crude midgut extracts) were used to determine the activity of digestive enzymes. In gypsy moth larvae, the digestive proteinase activities are attributed to serine proteinases responsible for the primary digestion of proteins. Trypsin is a serine proteinase that preferentially cleaves protein chains on the carboxyl side of basic L-amino acids. Leucine aminopeptidase catalyze the cleavage of amino acids from the amino terminus of protein or peptide substrates [48]. Alphaglucosidase catalyzes the hydrolysis of terminal, nonreducing 1,4-linked $\alpha$-D-glucose residues, releasing a-D-glucose from dietary small oligosaccharides [49], while lipases successively hydrolyze dietary triacylglycerols to di- and monoacylglycerols, with free fatty acids as coproducts. Additionally, lipases hydrolyze nitrophenyl esters at the oil-water interface [50]. Specific activity of total proteases (TP) [51], trypsin (TRY) and leucin aminopeptidase (LAP) [52], a-glucosidase $(\alpha-G)[53]$, and lipase (LIP) [54] were measured for each larval midgut extract in all experimental groups, and expressed as $U \mathrm{mg}^{-1}$ of midgut protein. Protein content was determined according to the methods of Bradford [55].

\subsection{Statistical analysis}

Standardized selection gradients were estimated in order to quantify intensity and direction of phenotypic selection acting on the digestive enzyme activity of gypsy moth larvae. As coefficients of partial regression, standardized selection gradients quantify (in units of phenotypic standard deviation; z-transformation [56]) the effect of each trait on relative fitness, holding the effects of all other traits constant [57]. Regression models were used to test for directional selection. Selection gradients were calculated for each of the experimental environments (control and treatment) in both Quercus and Robinia populations [58].

Following Schlichting [59], plasticity was measured as the absolute value of the differences in family mean enzyme phenotype between the two treatments (control and tannin-supplemented diets). The simplified statistical model of Scheiner and Berrigan [60] was used to estimate the cost of plasticity of enzyme activities within each of the treatments and each of the populations: $W=$ Constant $+\beta_{1}{ }^{*} X+\beta_{2}{ }^{*} X^{2}+\beta_{3}{ }^{*}$ pIX, where $W$ is the relative fitness in one environment/population, $X$ is the value of the trait in the complementary environment/ population, and pIX is the between-treatment plasticity of the analyzed trait. Significant regression coefficients $\beta_{1}$ and $\beta_{2}$ measure direct selection on the trait value and account for the linear and non-linear components of selection, while $\beta_{3}$ describes how the ability to be plastic 
affects fitness. Assuming that faster larval development is beneficial in the gypsy moth (see Introduction), a significant positive value of $\beta_{3}$ indicates the cost of maintaining the capacity for plastic responses, while a negative coefficient suggests the cost of homeostasis, i.e., beneficial effects of the ability to respond plastically to environmental conditions. The quadratic terms were not significant in preliminary tests and thus were removed from the analyses.

In both phenotypic selection analysis and plasticity cost analysis, relative fitness was estimated as the ratio of individual absolute fitness and average absolute fitness in both environments ( $\mathrm{C}$ and $\mathrm{T}$ ) within populations. Differences of standardized regression coefficients between diets within populations (QC-QT, $\mathrm{RC}-\mathrm{RT}$ ), and between the two populations on each diet (QC-RC, QT-RT) were tested by analysis of covariance [58].

\section{Results}

\subsection{Selection gradients}

Among estimated life-history traits, only the first observed period of larval development $\left(\mathrm{LD}_{4}\right)$ was shown to be sensitive to stressful concentrations of tannic acid (Table 1). Later larval stages $\left(L_{4}\right)$, as well as the total duration of assessed larval development $\left(L_{5}\right)$, maintained similar mean developmental durations in allelochemical stress as in the control environment. This result is not surprising for generalist species such as the gypsy moth, presuming the ability of these species to cope and maintain high fitness in a great number of circumstances. Selection analyses were performed in order to estimate the adaptivity or maladaptivity of enzyme plasticity and the contribution of adaptive enzyme plasticity to maintaining fitness across control and stressful environments. The phenotypic selection model applied on Quercus larvae in the control environment revealed that decreased activity of total proteases (TP) in all larval stages and of a-glucosidase $(\alpha-G)$ in the second assessed larval period $\left(L_{4}\right)$ was associated with shorter duration of the development (Table 2). This result implies that significantly lower mean activities of both enzymes in treatments with high tannin concentration (Table 1) may be considered to be an adaptive response to allelochemical stress. Though significant gradients in stress treatment were not detected, this was likely due to the joint influence of decreased variance of life-history and enzyme traits on the partial regression test (Table 2). Generally low values of selection gradients detected in the whole statistical model resulted in very high sensitivity to the variance levels. A negative functional relationship between increased activity of leucine aminopeptidase (LAP) and developmental time $\left(\mathrm{L}_{4}\right.$ and $\left.\mathrm{LD}_{5}\right)$ indicated the positive fitness effects of these enzymes in nonstressful environment. Similar to TP and $\alpha-G$ patterns, the trend of increasing mean LAP activity on the tanninsupplement treatment (Table 1) implied active adaptive response of this enzyme to dietary stress.

Regarding the Robinia population, in which the larvae evolved under higher levels of tannins, the influence of digestive enzymes on larval fitness differed in some aspects relative to the Quercus population (Table 2). In the Robinia population in the control environment,

\begin{tabular}{|c|c|c|c|c|c|c|c|c|c|c|c|c|}
\hline & \multicolumn{6}{|c|}{ Quercus population } & \multicolumn{6}{|c|}{ Robinia population } \\
\hline & \multicolumn{3}{|c|}{ control diet } & \multicolumn{3}{|c|}{ tannin-supplemented diet } & \multicolumn{3}{|c|}{ control diet } & \multicolumn{3}{|c|}{ tannin-supplemented diet } \\
\hline & $\mathrm{N}$ & $\bar{X}$ & SE & $\mathrm{N}$ & $\bar{X}$ & SE & N & $\bar{X}$ & SE & N & $\bar{X}$ & SE \\
\hline${ }^{1} \mathrm{LD}_{4}$ & 220 & 16.127 & $0.115^{\mathrm{abc}}$ & 241 & 15.983 & $0.126^{a c}$ & 178 & 16.635 & $0.177^{b}$ & 196 & 16.015 & $0.162^{\circ}$ \\
\hline $\mathrm{L}_{4}$ & 217 & 5.373 & $0.060^{\mathrm{a}}$ & 244 & 5.471 & $0.054^{\mathrm{a}}$ & 182 & 5.385 & $0.061^{a}$ & 202 & 5.460 & $0.071^{\mathrm{a}}$ \\
\hline${ }^{1} \mathrm{LD}_{5}$ & 219 & 21.438 & $0.138^{\mathrm{a}}$ & 235 & 21.434 & $0.148^{\mathrm{a}}$ & 177 & 22.006 & $0.192^{\mathrm{a}}$ & 194 & 21.412 & $0.187^{\mathrm{a}}$ \\
\hline${ }^{2} \mathrm{TP}$ & 215 & 1.824 & $0.042^{\mathrm{ab}}$ & 238 & 1.557 & $0.040^{\circ}$ & 176 & 1.996 & $0.055^{\mathrm{a}}$ & 193 & 1.746 & $0.045^{b}$ \\
\hline${ }^{3}$ TRY & 213 & 0.387 & $0.010^{\mathrm{ab}}$ & 239 & 0.307 & $0.007^{\circ}$ & 180 & 0.418 & $0.013^{\mathrm{a}}$ & 198 & 0.353 & $0.009^{b}$ \\
\hline${ }^{3} \mathrm{LAP}$ & 218 & 0.633 & $0.014^{a}$ & 244 & 0.671 & $0.015^{a}$ & 179 & 0.622 & $0.014^{a}$ & 189 & 0.656 & $0.014^{a}$ \\
\hline${ }^{2} \alpha-G$ & 217 & 1.058 & $0.030^{a}$ & 236 & 0.865 & $0.024^{b}$ & 174 & 0.905 & $0.032^{b}$ & 189 & 0.881 & $0.030^{b}$ \\
\hline ²ip & 212 & 0.918 & $0.020^{a}$ & 223 & 1.133 & $0.029^{b}$ & 175 & 0.885 & $0.023^{a}$ & 195 & 1.289 & $0.027^{\circ}$ \\
\hline
\end{tabular}

Table 1. Means and standard errors $(\bar{X} \pm \mathrm{SE})$ of three measures of developmental time and specific activity of digestive enzymes in gypsy moth larvae from Quercus and Robinia populations, reared on the control and on the tannin-supplemented diets; Numbers in a row that are followed by a different letter are significantly different $\left(P<0.05\right.$, Sheffe 's multiple range test); Data from ${ }^{1}[26],{ }^{2}[33]$ and ${ }^{3}[34]$; $\mathrm{N}=$ sample size. 
the activity of TP was not associated with larval fitness (except for $L_{4}$ ), while dependence of developmental time $\left(L_{5}\right)$ on activity of trypsin (TRY) was found, whereas this dependence was not found in the Quercus population. Interestingly, in contrast to the Quercus population where decreased activity of a-glucosidase $(\alpha-G)$ was related to increased larval fitness $\left(L_{4}\right)$, in the Robinia population higher levels of activity of this enzyme were correlated with faster development, hence the higher larval fitness. As in the Quercus population, most of selection gradients in stressful treatments failed to be detected as significant. However, active adaptive response to high tannin levels was statistically revealed for the increased activity of leucine aminopeptidase (LAP) in later larval phases and total development until the fifth instar $\left(L_{4}\right.$ and $\left.L_{5}\right)$.

Finally, the most pronounced adaptive response to allelochemical stress in both populations was found for the activity of lipase (Lip). For each larval stage (with the exception of $\mathrm{L}_{4}$ in the Robinia population), faster development was indubitably connected with increased activity of Lip (Table 2). Also, the levels of Lip activity were significantly higher in tannin-supplemented treatments compared to the control (Table 1).

Generally low values of selection gradients in the whole analysis resulted in mostly non-significant differences between experimental groups. As expected, significant differences were found between the two populations within control conditions (QC-RC comparison, Table 2) and for the enzymes previously noted as biomolecules with different plasticity patterns between populations, particularly for $\alpha$-glucosidase $(\alpha-G)(F=10.17, P<0.01$, Table 2). Adaptive lipase (Lip) response to dietary stress was revealed as significantly different between control and stress conditions within each population (QC-QT and RC-RT comparisons, Table 2). Similarity in patterns of stress responses of enzymes and mostly insignificant selection gradients in stressful conditions resulted in the absence of statistical differences between populations on the tanninsupplemented diet (QT-RT, Table 2).

\subsection{Cost of plasticity}

Selection analyses of the cost of ability to plastically respond to stressful conditions provided several evidences for both the cost of plasticity and the cost of homeostasis for digestive enzyme activity in Quercus larvae reared on the control diet. Generally, in the first three larval instars that were most sensitive to stress (i.e., $\mathrm{LD}_{4}$ life-history measure, Table 1), large plastic decrease of the activity of total proteases (TP) was costly, i.e., associated with low larval fitness (positive

\begin{tabular}{|c|c|c|c|c|c|c|c|c|c|}
\hline & & \multicolumn{4}{|c|}{ A. Standardized linear selection gradient $\left(\beta^{\prime}\right)$} & \multicolumn{4}{|c|}{ B. Comparisons } \\
\hline & & QC & QT & $\mathrm{RC}$ & RT & QC-QT & RC-RT & QC-RC & QT-RT \\
\hline \multirow[t]{5}{*}{$\mathrm{LD}_{4}$} & TP & $0.034^{\star}$ & 0.007 & -0.021 & 0.014 & 1.17 & 1.41 & $4.32^{\star}$ & 0.07 \\
\hline & TRY & -0.010 & 0.017 & 0.041 & 0.006 & 1.03 & 1.16 & 3.07 & 0.14 \\
\hline & LAP & -0.014 & -0.005 & $-0.037^{\star}$ & -0.034 & 0.34 & 0.02 & 1.81 & 1.88 \\
\hline & $\alpha-G$ & 0.003 & 0.001 & 0.021 & -0.012 & 0.02 & 3.04 & 1.16 & 0.58 \\
\hline & Lip & -0.009 & $-0.027^{\star}$ & 0.005 & $-0.027^{\star}$ & 1.52 & 3.20 & 0.79 & 0.00 \\
\hline \multirow[t]{5}{*}{$\mathrm{L}_{4}$} & $\mathrm{TP}$ & $0.068^{* \star}$ & 0.006 & $0.048^{*}$ & 0.032 & 3.33 & 0.20 & 0.36 & 0.48 \\
\hline & TRY & -0.041 & 0.023 & 0.017 & -0.009 & 3.36 & 0.41 & 2.62 & 0.68 \\
\hline & LAP & $-0.062^{* \star *}$ & -0.016 & -0.022 & $-0.057^{* *}$ & $4.28^{\star}$ & 1.72 & 3.58 & 2.24 \\
\hline & $\alpha-G$ & $0.029^{*}$ & 0.005 & $-0.035^{*}$ & -0.015 & 1.52 & 0.75 & $10.17^{\star \star}$ & 0.89 \\
\hline & Lip & -0.014 & $-0.035^{\star}$ & 0.015 & -0.0003 & 1.26 & 0.47 & 2.20 & 2.63 \\
\hline \multirow[t]{5}{*}{$\mathrm{LD}_{5}$} & TP & 0.034 & 0.008 & -0.010 & 0.018 & 1.44 & 1.33 & $4.16^{\star}$ & 0.17 \\
\hline & TRY & -0.009 & 0.020 & $0.046^{*}$ & -0.005 & 1.76 & 3.39 & $5.31^{\star}$ & 0.99 \\
\hline & LAP & $-0.030^{* * *}$ & -0.009 & $-0.036^{* *}$ & $-0.029^{*}$ & 2.24 & 0.13 & 0.18 & 1.23 \\
\hline & $\alpha-G$ & 0.004 & 0.003 & 0.006 & -0.007 & 0.01 & 0.75 & 0.01 & 0.54 \\
\hline & Lip & -0.003 & $-0.034^{\star \star \star *}$ & 0.011 & $-0.021^{*}$ & $6.12^{\star}$ & $4.53^{\star}$ & 1.22 & 0.77 \\
\hline
\end{tabular}

Table 2. Standardized linear $\left(\beta^{\prime}\right)$ selection gradients for digestive enzyme specific activity in gypsy moth larvae from Quercus $(Q)$ and Robinia (R) populations, reared on control (C) and tannin-supplemented (T) diets (within a row) (A). F-values obtained from ANCOVA for comparison of linear selection gradients between the diets within each population (QC-QT, RC-RT), and between the two populations within each diet (QC-RC, QT-RT) (B). $L D_{4}, L_{4}$, and $L D_{5}$ are indirect measures of fitness. 
value of regression coefficient, Table 3). This result was repeated in the analysis where larval developmental time until the fifth instar was used as a measure of fitness $\left(L D_{5}\right)$. Although in this experimental group low TP activity was positively selected (Table 2), the results of plasticity cost analysis suggested that for the same enzyme phenotype level, more plastic genotypes suffered greater fitness disadvantages compared with less plastic ones. For trypsin (TRY) and leucine aminopeptidase (LAP) activities in the first observed period of larval development $\left(\mathrm{LD}_{4}\right)$, we also revealed the costs of plasticity and homeostasis, respectively (Table 3), although no significant patterns of selection were revealed in phenotypic selection analyses (Table 2). On the other hand, the association of LAP and $\alpha$-glucosidase ( $\alpha-G$ ) activity with the $L_{4}$ fitness measure, and $L A P$ with $L D_{5}$ fitness trait, although significant in the control environment in Quercus population (Table 2), did not incur any plasticity cost. As expected from the selection analyses on lipase (Lip) activity, this active plastic response to stress did not confer any fitness disadvantage in any treatment. Moreover, deficiency in the ability to plastically react to variable conditions was found disadvantageous even in the control environment in the Quercus population (Table 3).
Except for a-glucosidase in larvae on the tanninsupplemented diet, in the Robinia population we found no evidence of a cost of plasticity of enzyme activities. In a population that evolved on a host plant with a higher tannin concentration, the evolution of plasticity in digestive enzymes could probably be an important course of adaptation.

\section{Discussion}

It has long been thought that tannins act as digestibility reducers [61]. However, studies on herbivores have demonstrated toxic effects of tannins due to production of reactive oxygen species after tannin autooxidation and oxidation in the gut lumen, which may further result in oxidative stress in midgut tissues and damage of the nutritional quality of food, especially proteins [62]. The ability of gypsy moth to tolerate increased levels of tannin oxidation in the midgut contents, with no harmful effects in surrounding tissue, indicates to strong biochemical defenses in larval midgut [22]. Responses of fitness traits to rearing on a tannin-supplemented diet could presume higher allocation of resources toward energy metabolism and defense than toward growth (sensu Hoffmann and

\begin{tabular}{|c|c|c|c|c|c|c|c|c|c|}
\hline & & \multicolumn{4}{|c|}{ A. Regression coefficients } & \multicolumn{4}{|c|}{ B. Comparison } \\
\hline & & QC & QT & $\mathrm{RC}$ & RT & QC-QT & $\mathrm{RC}-\mathrm{RT}$ & QC-RC & QT-RT \\
\hline \multirow[t]{5}{*}{$\mathrm{LD}_{4}$} & TP & $0.027^{* * *}$ & 0.014 & 0.008 & 0.001 & 1.24 & 0.20 & 1.94 & 0.97 \\
\hline & TRY & $0.016^{\star}$ & 0.0009 & 0.012 & 0.012 & 1.77 & 0.00 & 0.07 & 0.73 \\
\hline & LAP & $-0.016^{\star}$ & -0.011 & -0.014 & -0.012 & 0.21 & 0.02 & 0.04 & 0.00 \\
\hline & $\alpha-G$ & -0.009 & $-0.037^{* \star \star}$ & 0.002 & $0.021^{*}$ & $6.40^{\star}$ & 1.63 & 0.68 & $21.06^{\text {** }}$ \\
\hline & Lip & $-0.023^{* \star}$ & 0.0005 & -0.017 & -0.005 & 3.75 & 0.56 & 0.18 & 0.12 \\
\hline \multirow[t]{5}{*}{$\mathrm{L}_{4}$} & $\mathrm{TP}$ & 0.011 & 0.0002 & 0.030 & 0.009 & 0.50 & 1.33 & 1.29 & 0.27 \\
\hline & TRY & -0.011 & -0.003 & 0.015 & 0.004 & 0.31 & 0.34 & 2.22 & 0.15 \\
\hline & LAP & 0.0001 & -0.012 & -0.009 & -0.009 & 0.62 & 0.00 & 0.39 & 0.03 \\
\hline & $\alpha-G$ & -0.007 & 0.003 & -0.006 & 0.026 & 0.44 & 3.19 & 0.00 & 1.82 \\
\hline & Lip & $-0.038^{\star \star \star}$ & 0.002 & -0.010 & 0.013 & $5.77^{\star}$ & 1.26 & 2.65 & 0.30 \\
\hline \multirow[t]{5}{*}{$\mathrm{LD}_{5}$} & $\mathrm{TP}$ & $0.020^{\star *}$ & 0.009 & 0.016 & 0.001 & 1.20 & 1.39 & 0.13 & 0.51 \\
\hline & TRY & 0.012 & 0.0001 & 0.016 & 0.012 & 1.31 & 0.13 & 0.16 & 1.08 \\
\hline & LAP & -0.009 & -0.010 & -0.010 & -0.005 & 0.02 & 0.13 & 0.01 & 0.21 \\
\hline & $\alpha-G$ & -0.003 & $-0.028^{\star \star \star \star}$ & 0.0006 & $0.023^{\star \star}$ & $6.76^{\star \star}$ & 3.13 & 0.08 & $20.64^{\star \star \star}$ \\
\hline & Lip & $-0.029^{\star \star \star}$ & 0.0003 & -0.010 & -0.003 & $7.54^{\star \star}$ & 0.21 & 2.70 & 0.07 \\
\hline
\end{tabular}

Table 3. Regression analysis testing for plasticity costs of digestive enzyme specific activity in gypsy moth larvae from Quercus (Q) and Robinia (R) populations, reared on control $(C)$ and tannin-supplemented $(T)$ diets (within a row) (A). F-values obtained from ANCOVA for comparison of standardized regression coefficients for plasticity cost between the diets within each population (QC-QT, RC-RT), and between two populations within each diet (QC-RC, QT-RT) (B). $L_{4}, L_{4}$, and $L D_{5}$ are indirect measures of fitness.

${ }^{\star} P<0.05,{ }^{*} P<0.01,{ }^{* \star *} P<0.001$ 
Parsons [63]). Thus, the efficiency of exploiting the food proteins as tissue building blocks and carbohydrates or lipids as energy sources may significantly influence individual fitness. Since this efficiency depends on the activity of enzymes involved in protein, carbohydrate, and lipid digestion, variation in levels of enzyme activity will affect organismal performance. Complex regulatory mechanisms adjust digestive processes to changes in nutritional needs during development and under stress [64]. Differential synthesis and/or releasing of digestive enzymes have important roles in the maintenance of nutrient balance in different environments [14], and depending on the net fitness outcome of these complex physiological relations, some corresponding changes in enzyme activity may be favoured or eliminated by selection.

The analyses of enzyme phenotype selection revealed significant selection gradients mostly on gypsy moth larvae on a non-stressed diet compared with those on a tannin-supplemented diet. Although seemingly counterintuitive, the result is not surprising since the patterns of enzyme responses to dietary stress were found to be similar in both populations and resulted in decreased variance of response. However, this similarity implies important adaptive patterns of plasticity in reaction to stress. Decreased activity of total proteases and increased lipase activity in gypsy moth larvae from both Quercus and Robinia populations [33, and this study] are in accordance with increased needs for energy resources that could be allocated to defense, or used during the non-feeding pupal and adult stages. In a previous study on the gypsy moth, it was shown that older larvae invest more into antioxidant defense under stressful conditions [30]. Adaptive lower activities of total proteases in the control environment could be a postingestive homeostatic mechanism for nutrient rebalancing under the conditions of feeding on artificial diets where proteins are present in excess $[14,65]$. The opposite selection pattern for leucine aminopeptidase, i.e., positive selection for higher activity of leucine aminopeptidase on the control diets in both populations and on the tannin-supplemented diet in the Robinia population, implied that protease activity in regulating nutrient balance was associated with exopeptidase leucine aminopeptidase activity. Induced leucine aminopeptidase activity enables more efficient digestion of oligopeptides and production of more free amino acids for uptake. Lomate and Hivrale [16] also emphasize the adaptive significance of aminopeptidase induction in protein digestion under stressful conditions. Undeniably, the most evident inducible enzymatic response to dietary stress, which was clearly connected with higher larval relative fitness on the tannin-supplemented diet, was significantly higher lipase activity. As shown in gypsy moth larvae, lipids are very important for energy storage during advanced larval instars [66]. Since dietary lipids are richer sources of energy than proteins, higher lipase activity may provide efficient usage of dietary lipids and accordingly, acquisition of sufficient energy resources for induction of defense mechanisms in stressful environments. An interesting result that was revealed in this study was the detection of different patterns of selection acting on the activity of $\alpha$-glucosidase between the two populations. Being that selectively favoured decrease of $\alpha$-glucosidase activity in the Quercus population and increase of $\alpha$-glucosidase activity in the Robinia population were assessed in the control treatments, this result points to a long-term divergence of populations that evolved under distinct conditions. Adaptive higher $\alpha$-glucosidase activity in Robinia larvae, related to beneficial shorter development, could be the consequence of "stress selection", i.e., the transgenerational effect of feeding on nutritive-poor and tannin-rich locust-tree leaves $[27,28]$. As noted by Stojković et al. [67], "it is important to understand that immediate plastic responses to an unsuitable host influence the patterns of long-term adaptive evolution in insect populations, but, also, that adaptations across generations in the face of persisting exposure to low nutritional quality surely affect the short-term plastic reactions". The present results revealed lower activity of $\alpha$-glucosidase in gypsy moth larvae reared on tannin-supplemented diet (short-term effect). Inhibition of $\alpha$-glucosidase activity by some plant compounds was shown in insects [68], and tannic acid is known to inhibit $\alpha$-glucosidase activity in mammals [69]. Although decrease in $\alpha$-glucosidase activity is evident in both populations when tannic acid was added in the diet, the activity drop was not significant in the Robinia population, providing additional evidence for the imposed evolutionary change in enzyme plasticity. Long-term, transgenerational larval allelochemical stress caused by high concentration of tannins in the Robinia population may have led to selection favouring allelic variants that confer higher $\alpha$-glucosidase activity, at least in some larval developmental periods (e.g., $L_{4}$ ). The opposite trend of selection in the Quercus population requires further investigation of the relationship between $\alpha$-glucosidase activity and larval fitness. It may be hypothesized that optimal decrease of $\alpha$-glucosidase activity could result from homeostatic balancing with activities of other digestive enzymes evolved under a low-tannin diet. Simpson and Raubenheimer [70] showed that the effects of tannic acid on various characteristics of Locusta migratoria are highly dependent on the balance of macronutrients in the 
diet, i.e., on the protein:carbohydrate ratio. Caterpillars of various species tend to ingest either equal to or greater amount of proteins than carbohydrates, and this preference is likely to reflect the nutritive landscape of previous generations [71]. Therefore, optimal decrease of the $\alpha$-glucosidase activity in Quercus larvae could be the result of its adjustment with larval need for carbohydrates when they are present in excess.

Finally, this study found scant evidence for plasticity cost and/or cost of homeostasis. In light of evolutionary theory regarding evolution of plasticity, differences between the two populations were expected. In the Robinia population, which is a young population evolved under stressful conditions, evolution toward a high ability to plastically respond to environmental heterogeneity is highly probable [e.g., 5], thus, the costs of plasticity should not be significant. The only exception in this population was the cost of plastic decrease in $\alpha$-glucosidase activity in the presence of the stressor. Considering the trend toward reduced $\alpha$-glucosidase activity in larvae reared on the tannin-supplemented diet, it can be hypothesized that this plastic decrease was maladaptive as the consequence of organismal inability to maintain a constant phenotype when faced with detrimental circumstances [72], and may reflect limits of $\alpha$-glucosidase reaction norms [73] evolved in this population exposed to continuous stress. On the other hand, effects of tannin in the Quercus population revealed the importance of active plastic responses in

\section{References}

[1] Pigliucci M., Phenotypic Plasticity, John Hopkins University Press, Baltimore, 2001

[2] Via S., Lande R., Genotype-environment interaction and the evolution of phenotypic plasticity, Evolution, 39, 1985, 505-522

[3] Van Tienderen P.H., Evolution of generalists and specialist in spatially heterogeneous environments, Evolution, 1991, 45, 1317-1331

[4] Ghalambor C.K., Walker J.A., Reznick D.N., Multitrait selection, adaptation, and constraints on the evolution of burst swimming performance, Integr. Comp. Biol., 2003, 43, 431-438

[5] Ghalambor C.K., McKay J.K., Carroll S., Reznick D.N., Adaptive versus non-adaptive phenotypic plasticity and the potential for contemporary adaptation to new environments, Funct. Ecol., 2007, 21, 394-407

[6] Garland T. Jr., Kelly S.A., Phenotypic plasticity and experimental evolution, J. Exp. Biol., 2006, 209, 2344-2361

[7] Peppe F.B., Lomônaco C., Phenotypic plasticity of Myzus persicae (Hemiptera: Aphididae) raised $\alpha$-glucosidase activity, being that higher plasticity was accompanied with higher larval fitness, i.e., the cost of homeostasis was found. Additionally, in the Quercus population, the energetic and material costs of maintaining sensory and regulatory mechanisms that produce plastic response were found for some enzymes, such as total proteases and trypsin. Generally, in a population that evolved under more stable and favourable conditions, less plastic genotypes are expected to confer more fitness benefits than more plastic ones, presuming the action of stabilizing selection on trait values [74]. However, for leucine aminopeptidase, the sensitivity of activity levels was selectively favoured in the control conditions, while for lipase the sensitivity of activity levels was favoured in stressful conditions. These results in both populations suggest that this species has kept a high potential for further evolution of enzyme plasticity. Although these results are expected for generalist species such as Lymantria dispar, they are important for understanding the evolution of a physiological background that enables survival on a wide range of host plant species.

\section{Acknowledgements}

This work was supported by the Serbian Ministry of Education, Science and Technological Development, Grant No. 173027.

on Brassica oleracea L. var. acephala (kale) and Raphanus sativus L. (radish), Gen. Mol. Biol., 2003, 26, 189-194

[8] Marchand D., McNeil J.N., The importance of behavioral plasticity for maximizing foraging efficiency in frugivorous lepidopteran larvae, J. Insect Behav., 2004, 17, 673-685

[9] Haribal M., Renwick A.A., Plasticity in insect responses to variable chemistry of host plants, In: Ananthakrishnan T.N., Whitman D. (Eds), Insect Phenotypic Plasticity, Vol. 1: Diversity of Responses, Science Publishers, Inc., Enfield, 2005

[10] Görür G., Lomônaco C., Mackenzie A., Phenotypic plasticity in host-plant specialisation in Aphis fabae, Ecol. Entomol., 2005, 30, 657-664

[11] Leal-Aguilar K., Ruiz-Montoya L., Perales H., Morales $\mathrm{H}$., Phenotypic plasticity of Brevicoryne brassicae in responses to nutritional quality of two related host plants, Ecol. Entomol., 2008, 33, 735-741

[12] Broadway R.M., Dietary regulation of serine proteinases that are resistant to serine proteinase inhibitors, J. Insect Physiol., 1997, 43, 855-874 
[13] Chougule N.P., Giri A.P., Sainani M., Gupta V.S., Gene expression patterns of Helicoverpa armigera gut proteases. Insect Biochem. Mol. Biol. 2005, 35, 355-367

[14] Clissold F.J., Tedder B.J., Conigrave A.D., Simpson S.J., The gastrointestinal tract as a nutrientbalancing organ, Proc. R. Soc. B, 2010, 277, 1715-1759

[15] War A.R., Panlraj M.G., Hussain B., Buhroo A.A., Ignacimuthu S., Sharma H.C., Effect of plant secondary metabolites on legume pod borer, Helicoverpa armigera, J. Pest Sci., 2013, 86, 399-408

[16] Lomate P.R., Hivrale V.K., Differential responses of midgut soluble aminopeptidases of Helicoverpa armigera to feeding on various host and non-host plant diets, Arthropod-Plant Inte., 2011, 5, 359-368

[17] Yazdani E., Sendi J.J., Aliakbar A., Chemical composition,toxicity and physiological effects of essential oil of Rosemarinus officinalis on lesser mulberry pyralid, Glyphodes pyloalis Walker (Lepidoptera: Pyralidae), J. Crop Prot., 2013, 2, 461-476

[18] Pankoke H., Deane Bowers M., Dobler S., Influence of iridoid glycoside containing host plants on midgut $\beta$-glucosidase activity in a polyphagous caterpillar, Spilosoma virginica Fabricius (Arctiidae), J. Insect Physiol., 2010, 56, 1907-1912

[19] Srinivasan A., Ashok G.P., Gupta V.S., Structural and functional diversities in lepidopteran serine proteases, Cell. Mol. Biol. Lett., 2006, 11, 132-154

[20] Zhu-Salzman K., Bi J-L., Liu T-X., Molecular strategies of plant defense and insect counterdefense, Insect Sci., 2005, 12, 3-15

[21] Liebhold A.M., Gottschalk K.W., Muzika R.M., Montgomery M.E., Young R., O`Day K., Kelly B., Suitability of North American tree species to gypsy moth: a summary of field and laboratory tests, General Technical Report NE-211, USDA Forest Service, Randor, PA, 1995

[22] Barbehenn R.V., Jaros A., Lee G., Mozola C., Weir Q., Salminen J-P., Hydrolyzable tannins as "quantitative" defenses: limited impact against Lymantria dispar caterpillars on hybrid poplar, J. Insect Physiol., 2009, 55, 297-304

[23] Schultz J.C., Baldwin I.T., Oak leaf quality declines in response to defoliation by gypsy moth larvae, Science, 1982, 217, 149-151

[24] Rossiter M., Schultz J.C., Baldwin I.T., Relationships among defoliation, red oak phenolics, and gypsy moth growth and reproduction, Ecology, 1988, 69, 267-277

[25] Bourchier R.S., Nealis V.G., Development and growth of early- and late-instar of gypsy moth
(Lepidoptera: Lymantriidae) feeding on tanninsupplemented diets, Environ. Entomol., 1993, 22, 642-646

[26] Mrdaković M., Perić-Mataruga V., Ilijin L., Vlahović M., Todorović D., Nenadović V., et al., The effects of tannic acid on the fitness-related traits of Lymantria dispar L. larvae, Arch. Biol. Sci. (Belgrade), 2011, 63, 1037-1045

[27] Montgomery M.E., Gypsy moth host plant relationships and population dynamics, In: Proceeding 18th IUFRO World Congress, Division 2, Vol. II: Forest Plants and Forest Protection, Ljubljana, Slovenia, 1986, 743-754

[28] Unruh-Snyder L.J., Luginbuhl L-M., Mueller J.P., Conrad A.P., Turner K.E., Intake, digestibility and nitrogen utilization of Robinia pseudoacacia foliage fed to growing goat wethers, Small Rumin. Res., 2007, 71, 179-193

[29] Sidor Ć., Jodal I., Results of investigations of health conditions of gypsy moth (Porthetria dispar L.) in acacia forest "Bagremara", Plant Prot., 1983, 34, 445-455

[30] Perić-Mataruga V., Blagojević D., Spasić M.B., Ivanović J., Janković-Hladni M., Effect of the host plant on the antioxidative defence in the midgut of Lymantria dispar L. caterpillars of different population origins, J. Insect Physiol., 1997, 43, 101-106

[31] Lazarević J., Perić-Mataruga V., Stojković B., Tucić N., Adaptation of the gypsy moth to an unsuitable host plant, Entomol. Exp. Appl., 2002, 102, 75-86

[32] Lazarević J., Perić-Mataruga V., Prolić Z., Tucić N., Behavioural response to an unsuitable host plant in the gypsy moth (Lymantria dispar L.), Folia Biol. (Krakow), 2003, 51, 129-131

[33] Mrdaković M., Perić-Mataruga V., Ilijin L., Vlahović M., Janković-Tomanić M., Mirčić D., et al., Response of Lymantria dispar (Lepidoptera: Lymantriidae) larvae from differently adapted populations to allelochemical stress: effects of tannic acid, Eur. J. Entomol., 2013, 110, 55-63

[34] Mrdaković M., Perić-Mataruga V., Ilijin L., Vlahović M., Todorović D., Nenadović V., et al., Effects of tannic acid on trypsin and leucine aminopeptidase activities in gypsy moth larval midgut, Arch. Biol. Sci., Belgrade, 2013, 65, 1405-1413

[35] Nylin S., Gotthard K., Plasticity in life-history traits, Annu. Rev. Entomol., 1998, 43, 63-83

[36] Slansky F., Nutritional ecology: the fundamental quest of nutrients, In: Stamp N.E., Casey T.M. (Eds), Caterpillars: ecological and evolutionary constraints on foraging, Chapman and Hall, New York, 1993 
[37] Benrey B., Denno R.F., The slow growth-high mortality hypothesis: a test using the cabbage butterfly, Ecology, 1997, 78, 987-999

[38] Lindroth R.L., Bloomer M.S., Biochemical ecology of the forest tent caterpillar: responses to dietary protein and phenolic glycosides, Oecologia, 1991, $86,408-413$

[39] Beninger C.W., Abou-Zaid M.M., Flavonol glycosides from four pine species that inhabit early instar gypsy moth (Lepidoptera: Lymantriidae) development, Biochem. Syst. Ecol., 1997, 25, 505-512

[40] Hochuli D.F., Insect herbivory and ontogeny: how do growth and development influence feeding behavior, morphology and host use?, Austral. Ecol., 2001, 26, 563-570

[41] Zalucki M.P., Clarke A.R., Malcolm S.B., Ecology and behavior of first instar larval lepidoptera, Annu. Rev. Entomol., 2002, 47, 361-393

[42] Rossiter M.C., Genetic and phenotypic variation in diet breadth in a generalist herbivore, Evol. Ecol., 1987, 1, 272-282

[43] Lindroth R., Klein K.A., Hemming J., Feuker A.M., Variation in temperature and dietary nitrogen affect performance of the gypsy moth (Lymantria dispar L.), Physiol. Entomol., 1997, 22, 55-64

[44] Martemyanov V.V., Dubovskiy I.M., Belousova I.A., Pavlushin S.V., Domrachev D.V., Rantala M.J., et al., Rapid induced resistance of silver birch affects both innate immunity and performance of gypsy moth; the role of plant chemical defenses, Arthropod-Plant Inte., 2012, $6,507-518$

[45] Lazarević J., Perić-Mataruga V., Ivanović J., Anđelković M., Host plant effects on the genetic variation and correlations in the individual performance of the gypsy moth, Funct. Ecol., 1998, $12,141-148$

[46] Janković-Tomanić M., Lazarević J., Effects of temperature and dietary nitrogen on genetic variation and covariation in gypsy moth larval performance, Arch. Biol. Sci. (Belgrade), 2012, 64, $1109-1116$

[47] O'Dell T.M., Butt C.A., Bridgeforth A.W., Lymantria dispar, In Singht P., Moore R. (Eds.) Handbook of Insect Rearing, Elsevier, New York, 1985

[48] Valaitis A.P., Gypsy moth midgut proteinases: purification and characterization of luminal trypsin, elastase and the brush border membrane leucine aminopeptidase, Insect Biochem. Molec. Biol., 1995, 25, 139-149

[49] Terra W.R., Ferreira C., Jordao B.P., Dillon R.J., Digestive Enzymes, In: Lehane M.J., Billingsley
P.F. (Eds.), Biology of the Insect Midgut, Chapman \& Hall, London, 1996, 153-193

[50] Beisson F., Tiss A., Riviere C., Verger R., Methods for lipase detection and assays: a critical review, Eur. J. Lipid Sci. Technol., 2000, 102, 133-153

[51] Kunitz M., Crystalline soybean trypsin inhibitor. II. General properties. J. Gen. Physiol., 1947, 30, 291-310

[52] Erlanger B.F., Kokowski N., Cohen W., The preparation and properties of two new chromogenic substrates of trypsin, Arch. Biochem. Biophys., 1961, 95, 271-278

[53] Baker J.E., Properties of glycosidases from the maize weevil, Sitophilus zeamais, Insect Biochem., 1991, 21, 615-621

[54] Mrdaković M., Lazarević J., Perić-Mataruga V., Ilijin L., Vlahović M., Partial characterization of a lipase from gypsy moth (Lymantria dispar L.) larval midgut, Folia Biol. (Krakow), 2008, 56, 103-110

[55] Bradford M., A rapid and sensitive method for the quantification of microgram quantities of protein utilizing the principle of protein-dye binding, Anal. Biochem., 1976, 72, 248-254

[56] Sokal R.R., Rohlf F.J., Biometry, Freeman, San Francisco, 1981

[57] Lande R., Arnold S.J., The measurement of selection on correlated characters, Evolution, 1983, 37, 1210-1226

[58] SAS Institute, Inc 2003 The SAS System for Windows. Release 9.1. SAS Institute, Cary, NC, USA

[59] Schlichting C.D., 1986 The evolution of phenotypic plasticity in plants, Ann. Rev. Ecol. Syst, 17, 667-694

[60] Scheiner S.M., Berrigan D., The genetics of phenotypic plasticity. VIII. The cost of plasticity in Daphnia pulex, Evolution, 1998, 52, 545-555

[61] Feeny P., Inhibitory effect of oak leaf tannins on the hydrolysis of proteins by trypsin, Phytochemistry, 1969, 8, 2119-2126

[62] Barbehenn R.V., Constabel P.C., Tannins in plantherbivore interactions, Phytochemistry, 2011, 72, 1551-1565

[63] Hoffman A.A., Parsons P.A., Evolutionary genetics and environmental stress, Oxford University Press, Oxford, 1991

[64] Bede J.C., McNeil J.N., Tobe S.S., The role of neuropeptides in caterpillar nutritional ecology, Peptides, 2007, 28, 185-196

[65] Janković-Tomanić M., Effects of temperature and food quality on variability of fitness components and physiology of digestion in the gypsy moth larvae Lymantria dispar L., Ph.D. thesis, 
University of Belgrade, Belgrade, Serbia, 2012, (in Serbian)

[66] Stockhoff B.A., Ontogenetic change in dietary selection for protein and lipid by gypsy moth larvae, J. Insect Physiol., 1993, 39, 677-686

[67] Stojković B., Šešlija-Jovanović D., Tucić N., Transgenerational effects on overall fitness: influence of larval feeding experience on the oviposition behaviour of seed beetle Acanthoscelides obtectus (Say), Pol. J. Ecol., 2012, 60, 387-393

[68] Zibaee A., Bandani A.R., Effects of Artemisia annua $L$ (Asteraceae) on the digestive enzymatic profiles and the cellular immune reactions of the Sunn pest, Eurygaster integriceps (Heteroptera: Scutellaridae), against Beauveria bassiana, Bull. Entomol. Res., 2010, 100, 185-196

[69] Chauhan A., Gupta S., Mahmood A., Effect of tannic acid on brush border disaccharidases in mammalian intestine, Indian J. Exp. Biol., 2007, 45, 353-358

[70] Simpson S.J., Raubenheimer D., The geometric analysis of nutrient-allelochemical interactions: a case study using locusts, Ecology, 2001, 82, 422-439

[71] Behmer S.T., Insect Herbivore Nutrient Regulation, Annu. Rev. Entomol., 2009, 54, 165-187

[72] Alpert P., Simms E.L., The relative advantages of plasticity and fixity in different environments: when is it good for a plant to adjust?, Evol. Ecol., 2002, 16, 285-297

[73] DeWitt T.J., Sih A., Wilson D.S., Costs and limits of phenotypic plasticity, Trends Ecol. Evol., 1998, 13, 77-81

[74] Griffith T., Sultan S.E., Shade tolerance plasticity in response to neutral versus green shade cues in Polygonum species of contrasting ecological breadth, New Phytol., 2005, 166, 141-148 